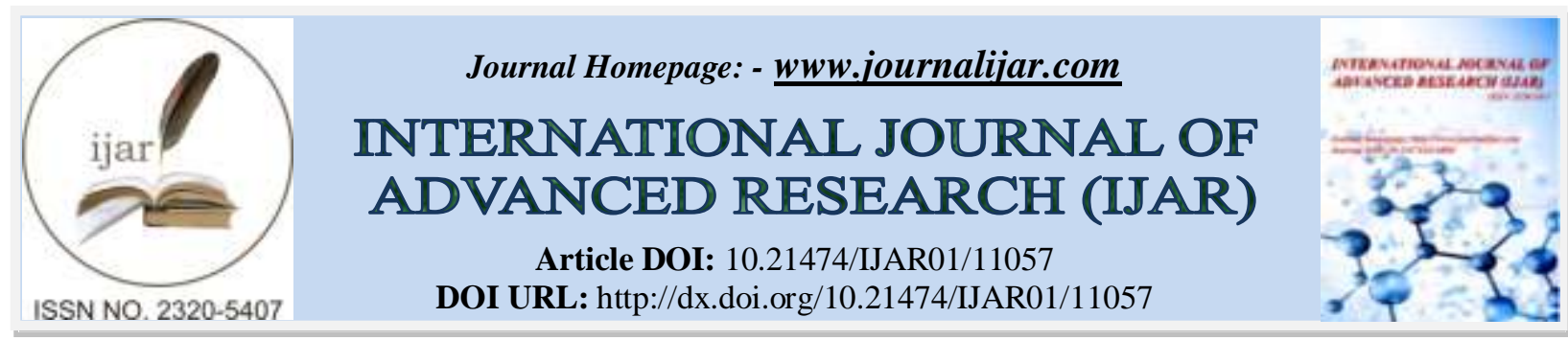

RESEARCH ARTICLE

\title{
PLACENTAL BLOOD DRAINAGEIN ACTIVE MANAGEMENT OF THIRD STAGE OF LABOUR AFTER VAGINAL DELIVERY
}

Dr. Shagufta Rather, Dr. Ambreen Qureshi, Dr. Sumeena and Dr. Nazeefa

Department of Obstetrics and Gynaecology, Govt. Medical College, Srinagar.

Manuscript Info
Manuscript History
Received: 25 March 2020
Final Accepted: 30 April 2020
Published: May 2020
Key words:-
Labour, Postpartum Haemorrhage,
Primigravida

Labour, Postpartum Haemorrhage,

\begin{abstract}
Background: Labour is a physiologic process during which the fetus, membranes, umbilical cord and placenta are expelled from the uterus. The process of labour is divided into three stages: Stage I: Commences with the start of labour pains and ends with full dilatation of the cervix. Stage II: Begins with full dilatation of the cervix and ends with complete expulsion of the fetus. Stage III: This stage commences with the delivery of entire fetus and ends with the delivery of placenta and membranes.

Objectives: (i) Estimate the duration of third stage of labour in patients in whom placental blood drainage was done and those patients in whom placental blood was not drained. (ii) Measure the amount of blood loss in those with PBD and in those in whom PBD is not done. (iii) Measure the fall in Haemoglobin concentration 48 hours following delivery in both groups.

Methods: This was a prospective, hospital based, case control study conducted in the Post Graduate Department of Obstetrics and Gynaecology, Lal Ded Hospital, Government Medical College, Srinagar. Hundred patients with term pregnancy $(\geq 37$ weeks of gestation) with single live foetus undergoing normal vaginal delivery were included in the study. Patients were randomly allocated into two groups, one with 50 patients in whom PBD was done and another group of 50 patients in whom PBD was not done.

Results: In the present study, the average age of the patients was 30.4 years in study group and 30.7 years in the control group. The mean gestational age at delivery in our study was 38.5 and 38.8 weeks in the study and control group, respectively. Primigravida formed the biggest group (34\%) in the study group in our study, while women with second pregnancy formed the most populous group (36\%) in control series. The mean duration of the third stage was 170.2 seconds in the cases group in contrast to 248.3 seconds in the control group. (p-value $<0.001)$. The mean blood loss in cases group was $171.8 \mathrm{ml}$ while in patients belonging to control group, the mean blood loss was measured to be $234.7 \mathrm{ml}$. (p-value <0.001). None of the patients in cases group developed PPH while $4 \%$ of the control patients developed PPH in the post-partum period. None of the patients in the case series required blood transfusion while 2 patients (4\%) in the control series required blood transfusion.
\end{abstract}


Conclusion: From the present study, it can be concluded that placental blood drainage as part of active management of third stage of labour is effective in reducing the duration of third stage of labour. The amount of blood loss and also the incidence of PPH. It is a procedure which needs minimal expertise, can be practiced in rural settings with limited number of specialists, even by trained birth attendants. In addition it can be practiced safely in patients in whom volume overload is to be avoided.

Copy Right, IJAR, 2020,. All rights reserved.

\section{Introduction:-}

Labour is a physiologic process during which the fetus,membranes,umbilical cord and placenta are expelled from the uterus.Despite being a physiological process, it is often associated with some morbidity and mortality,most commonly related to blood loss during the process ${ }^{1}$. The third stage of labor is the most crucial stage as postpartum hemorrhage (PPH) during this stage can cause significant maternal morbidity and mortality. PPH is the leading cause of maternal death worldwide, with an estimated mortality rate of 140,000 per year, or one maternal death every 4 minutes $^{2}$.

The third stage of labor is managed using two approaches: active management and expectant management. Active management involves administration of oxytocic drugs, cord clamping and cutting as well as controlled cord traction.Recently placental blood drainage (PBD) is being promoted as part of active management of third stage of labor. Placental blood drainage involves clamping and cutting of the umbilical cord after delivery of the baby and immediately afterwards unclamping the maternal side of the cord and allowing the blood from the placenta to drain freely $^{3}$. It has been suggested that draining blood from the placenta would reduce its bulkiness, allowing the uterus to contract and retract and thus aiding delivery of placenta. It could therefore help in prevention of PPH as well as its associated morbidity and mortality ${ }^{4}$.

\section{Methods:-}

A prospective case control study was conducted over a period of eighteen months(December 2017 to July 2019) in the Department of Obstetrics and Gynecology, Lalla Ded Hospital, Government Medical College Srinagar in which one hundred patients with term pregnancy with single live fetus undergoing normal vaginal delivery were included.The patients were allocated to two groups, one who were subjected to PBD and another in whom PBD was not done. Inclusion criteria were singleton pregnancy of 37 weeks or more with vertex presentation with no obstetric complications and with spontaneous onset of labor. Women who were anemic $(\mathrm{Hb}<7 \mathrm{~g} / \mathrm{dl})$, with history ofantepartum hemorrhage or previous surgery on uterus, women with malpresentations, overdistended uterus,coagulopathy,instrumental delivery or in whom labor was induced were excluded from the study.Active management of third stage was done in both groups using prophylactic oxytocin except for the single variable studied.Duration of third stage of labor,blood loss in both groups, amount of blood drained from placenta in group 1 and fall in $\mathrm{Hb}$ concentration 48 hours following delivery were recorded in both groups. The recorded data was compiled andanalyzed.

\section{Results:-}

The mean age of patients was comparable in both groups i.e., 30 - 31years.Primigravida were the largest group in cases and second gravidas in the control group.Mean gestational age was 38 to 39 weeks in both the groups. The baseline hemoglobin was comparable in both the groups. It was seen that the duration of third stage of labor was reduced significantly in the cases group as compared to the controls.It was around $170.2 \mathrm{sec}$ in cases group and $248.3 \mathrm{sec}$ in control group.

Table 1:- Duration of Third stage of labour.

\begin{tabular}{|l|l|l|l|l|l|}
\hline (Seconds) & N & Mean & SD & Range & P-value \\
\hline Cases & 50 & 170.2 & 51.73 & $55-330$ & $<0.001^{*}$ \\
\hline Controls & 50 & 248.3 & 117.12 & $105-660$ & \\
\hline
\end{tabular}

As regards the amount of blood loss it was seen that the mean blood loss in cases was $171.8 \mathrm{ml}$ and $234.7 \mathrm{ml}$ in controls. This difference was statistically significant. 
Table 2:- Fall of maternal $\mathrm{Hb}(\mathrm{gm} / \mathrm{dl})$ after 48 hours of delivery between cases \& controls.

\begin{tabular}{|l|l|l|l|l|l|}
\hline Fall of Maternal $\mathbf{H b}(\mathbf{g m} / \mathbf{d l})$ & $\mathbf{N}$ & Mean & SD & Range & P-value \\
\hline Cases & 50 & 0.46 & 0.237 & $0.1-1$ & $<0.001$ \\
\hline Controls & 50 & 0.98 & 0.711 & $0-3.3$ & \\
\hline
\end{tabular}

It was observed that the average fall in hemoglobin level after $48 \mathrm{hrs}$ of delivery was also statistically significant amongst the two groups. It was $0.46 \mathrm{~g} / \mathrm{dl}$ in cases and $0.98 \mathrm{~g} / \mathrm{dl}$ in controls.

Table 3:- Comparison based on amount of blood loss (ml) between cases and controls.

\begin{tabular}{|l|l|l|l|l|l|}
\hline Amount of blood loss (ml) & N & Mean & SD & Range & P-value \\
\hline Cases & 50 & 171.8 & 51.61 & $800-300$ & $0.002 *$ \\
\hline Controls & 50 & 234.7 & 126.61 & $85-700$ & \\
\hline
\end{tabular}

None of the patients in the placental blood drainage group had PPH whereas two patients amongst the control group had PPH. These two patients required blood transfusion as well.No patient in the cases or control group had retained placenta.

\section{Discussion:-}

Third stage of labor is the most vital stage amongst the stages of labor.Any untoward event in this stage can be fatal to the mother, be itPPH, retained placenta or embolism. Active management of third stage of labor was introduced to prevent such complications and save precious lives.

Placental blood drainage is one such suggested method in the active management of third stage of labor in which clamping and cutting of umbilical cord after delivery of the baby is followed by immediately unclamping the maternal side of the cord to allow the blood in the placenta to drain freely from it.

Thisobservational prospective comparative study was performed to measure the effect of placental blood drainage on various parameters in low-risk pregnancies associated with active management of third stage of labor. The amount of blood loss during the third stage of labor and total duration of the third stage were adopted as major outcome variables. 100 Women with singleton pregnancy in vertex presentation with gestational age more than or equal to 37 weeks, with no obstetric complications who underwent spontaneous vaginal delivery were included in the study.

Among these fifty were subjected to placental blood drainage(cases) and fifty were not(control). Placental blood drainage was shown to significantly reduce the mean duration of third stage of labor (170.2 secs as compared to 248.3 secs in control group) which is comparable with the findings of Gulati N et al. [(2001) ${ }^{5} ; 2.94$ and 5.72 minutes in cases and control], Dutta BK et al $\left[(2017)^{6} ; 5.57\right.$ and 7.41 minutes while as Asicioglu O et al $\left[(2015)^{7}, 3.5\right.$ min and $7.7 \mathrm{~min}$, respectively.

The average blood loss in the cases was significantly reduced (it was $171.8 \mathrm{ml}$ as compared to $234.7 \mathrm{ml}$ in controls). The mean drop in hemoglobin cases was also less $(0.46 \mathrm{~g} / \mathrm{dl}$ in cases as compared to $0.98 \mathrm{~g} / \mathrm{dl}$ in controls.). None of the patients in the cases group had complicationsof third stage like PPH or retained placenta.

Placental blood drainage (PBD) helped reduce the amount of blood loss during the third stage of labour as was seen by Upadhya R et al. $(2019)^{8}$, Gulati N et al. $(2001)^{5}$, Meena SA et al. (2017) ${ }^{9}$, Roy P et al $(2016)^{10}$, and Sreelatha S et al $(2013)^{11}$. Significant difference in the fall of Hb levels postpartum, and difference in Hb levels was also shown by Roy P et al $(2016)^{10}$, Meena SA et al (2017) ${ }^{12}$ and Giacalone PL et al (2000) ${ }^{13}$ closely corroborate with the findings of our study. Among the below studies Meena SA et al (2017) ${ }^{12}$ observed the smallest drop in hemoglobin levels in both groups $\left(0.28\right.$ vs 0.68) while as Osman Asicioglu O et al $(2015)^{7}$ estimated the largest drop in postpartum hemoglobin levels ( 1.1 vs 1.9 ). Gulati $\mathrm{N}$ et al (2001) $)^{5}$, Jongkolsiri P et al (2009) ${ }^{14}$, Shravage JC et al $(2007)^{15}$, Sreelatha S et al $(2013)^{11}$, and, Asicioglu O et al $(2015)^{7}$ also observed no cases of placental retention in patients in the study group. However these studies observed that some patients in their control group developed retention of placenta. 


\section{Conclusion:-}

Postpartum haemorrhage (PPH), a complication of third stage of labor is the leading cause of maternal morbidity and mortality worldwide. Management targeted at reducing its incidence involves early detection and timely intervention. Active Management in Third Stage of Labor (AMTSL) as approved by FIGO in 2003 has gone a long way in preventing PPH.Placental Blood Drainage (PBD) as part of active management of third stage oflabor is effective in reducing the duration of third stage, the amount of blood loss and also the incidence of PPH.

It is a simple, safe and noninvasive method which requires minimal expertise and can be practiced in tertiary as well as rural settings with limited number of specialists, even by trained birth attendants. In addition, it is preferred in patients in whom volume overload is to be avoided. However further multicentric studies are needed before it can be incorporated as part of AMTSL.

\section{Bibliography:-}

1. Henry DA et al. Antifibrinolytic use for minimizing perioperative allogenic blood transfusion: Cochrane database of systematic reviews, 2007; Issue 4. Art No. CD001886.

2. AbouZahr C. Global burden of maternal death and disability. Br Med Bull 2003; 67:1-11.

3. Soltani H, Dickinson F, Symonds IM. Placental cord drainage after spontaneous vaginal delivery as part of the management of the third stage of labour. Cochrane Database of Systematic Reviews 2005, Issue 4. Art. No.: CD004665

4. Wood J, Rogers J. The third stage of labour. In: Alexander J, Levy V, Roth C editor(s). Midwifery practice: core topics 2. London: MacMillan Press Ltd, 1997.

5. Gulati N, Chauhan MB, Rana M. Placental blood drainage in management of third stage of labour. J Obst. Gyn. India, 2001; Vol. 51, No. 6: pg 46-48.

6. Dutta BK, Mahanta M. Prevention of blood loss in third stage of labour by placental blood drainage- a clinical study. J. Evid. Based Med. Healthc. 2017; Vol. 4, Issue 94.

7. Asicioglu O, Unal C, Asicioglu BB, Temizkan O, Yildirım G, Arici B, Gulova S. Influence of placental cord drainage in management of the third stage of labor: a multicenter randomized controlled study. Am J Perinatol. 2015 Mar;32(4):343-50.

8. Upadhya R, Rani C, Poojari VG and Pai MV. The maternal side of placental cord blood drainage in the management of the third stage of labor: Relook the basic step in minimizing the maternal blood loss. International Journal of Clinical Obstetrics and Gynaecology 2019; 3(5): 144-147.

9. Meena SA, Bebincy DS, Devika. Placental cord blood drainage after vaginal delivery as part of the management of third stage of labour: a systematic review of randomized controlled clinical trial. Int J Reprod Contracept Obstet Gynecol 2017;6:4001-5.

10. Roy P, Sujatha MS, Bhandiwad A, Biswas B, Chatterjee A. Placental blood drainage as a part of active management of third stage of labour after spontaneous vaginal delivery. The Journal of Obstetrics and Gynaecology India, 2016 Oct; 66(Suppl 1): 242-5.

11. Sreelatha S, Nayak V, Kazi A. Effect of placental cord blood drainage on the third stage of labour. Journal of Evolution of Medical and Dental Sciences 2013; Volume 2, Issue 21.

12. Cotter A, Ness A, and Tosola J. Prophylactic oxytocin for the third stage of labour. Cochrane database Syst Rev, 2001; 4.

13. Giacolone PL, Vignal J, Daures JP, Boulot P, Hedon B, Laffargue F. A randomised evaluation of two techniques of management of the third stage of labour in women at low risk of postpartum haemorrhage. BJOG. 2000;107:396-400.

14. Jongkolsiri P, Manotaya S. Placental cord drainage and the effect on the duration of third stage labour, a randomized controlled trial. J Med Assoc Thai. 2009 Apr;92(4):457-60.

15. Shravage JC, Silpa P. Randomized controlled trial of placental blood drainage for the prevention of postpartum hemorrhage. J Obstet Gynaecol India. 2007;57:214-16.

16. Sreelatha S, Nayak V, Kazi A. Effect of placental cord blood drainage on the third stage of labour. Journal of Evolution of Medical and Dental Sciences 2013; Volume 2, Issue 21. 